\title{
El Abrigo del Melgar. Nuevas apreciaciones cronológicas sobre las pinturas esquemáticas del núcleo de Quesada (Jaén)
}

\author{
Miguel Soria Lerma * y Manuel Gabriel López Payer **
}

\begin{abstract}
RESUMEN
En este artículo se presenta el Abrigo del Melgar (Sierra de Quesada), el cual contiene una serie de pinturas que aportan nuevos datos con relación a la cronología y el significado del arte rupestre esquemático del Sudeste de

la Península Ibérica. Se sitúa la realización de estas representaciones en la Edad del Cobre, y se intenta precisar la cronología de la estación dentro del núcleo de Quesada.
\end{abstract}

\section{PALABRAS CLAVE}

Arte rupestre, postpaleolitico, Edad del Cobre, arte mueble, decoraciones cerámicas.

\section{ABSTRACT}

This article concerns the Melgar rock shelter (Quesada Mountain Range), which contains a series of paintings that provides new information about the chronology and meaning of schematic rock art in the Southeast of the Iberian Peninsula. The achievement of these pictures it's dated in the Copper Age, and the chronology of the station has been tried to fix within the Quesada group.

\section{KEY WORDS}

Rock art, postpalaeolithic, Copper Age, portable or mobiliary art, ceramic decorations.

* Miembro del equipo de elaboración del informe de propuesta de Declaración como Patrimonio de la Humanidad del Arte Rupestre del Arco Mediterráneo Español en Andalucía.

** Director de proyecto de investigación «El arte rupestre en el Alto Guadalquivir y su relación con el poblamiento prehistórico». 


\section{INTRODUCCIÓN}

La reciente declaración como Patrimonio de la Humanidad de todos los conjuntos que integran el Arte Rupestre del Arco Mediterráneo Español, efectuada por la UNESCO el 2 de diciembre de 1998 en Kioto, ha supuesto, sin duda alguna, el definitivo espaldarazo para una de las manifestaciones artísticas más genuinas de la Prehistoria peninsular y europea.

Bajo el citado epígrafe se engloban una serie de realizaciones pictóricas que, teniendo como núcleos centrales los yacimientos con arte levantino, incluyen también a cuantos conjuntos rupestres se encuentran en su entorno próximo, todos los cuales reunen unos requisitos que los hacen merecedores del citado reconocimiento y que se refieren esencialmente a su exclusividad territorial, a su excepcionalidad histórica y a su vulnerabilidad y fragilidad como características que hacen muy necesaria su protección y conservación. Por todo ello, este evento va a suponer la definitiva puesta en valor, la protección y la adecuada difusión del arte prehistórico de toda la región mediterránea y, en consecuencia, de una buena parte de las pinturas rupestres que se albergan en las serranías giennenses. En este sentido, dicha declaración ha supuesto también el reconocimiento de una labor investigadora que iniciamos hace ya más de veinticinco años y que, entre otros logros, ha conseguido la inclusión de la no despreciable cifra de 42 yacimientos de la provincia de Jaén en la lista del Patrimonio Mundial.

Esa cuarentena de conjuntos se encuentran ubicados en los núcleos de las sierras de Segura, Quesada y Aldeaquemada, y aunque todos ellos, según la Ley del Patrimonio Histórico Español de 1985, eran considerados como Bienes de Interés Cultural, no cabe duda que la nueva declaración va a potenciar su estudio, difusión y conservación.

De los núcleos referidos, los conjuntos de Aldeaquemada habían sido ya publicados a principios de siglo (Cabré, 1917; Breuil, 1933) y revisados posteriormente por nosotros (López Payer y Soria Lerma, 1988), mientras que los de las sierras de Quesada y Segura, a pesar de que ya han sido publicadas una parte de sus pinturas, una buena parte de las mismas siguen inéditas y están sometidas a estudio. Este es el caso del abrigo que aquí presentamos, el Abrigo del Melgar, cuyo interés no sólo radica en su reciente inclusión en el Patrimonio de la Humanidad, sino en el hecho de albergar una serie de figuras que aportan importantes datos en orden a la profundización de aspectos tan debatidos como la cronología y el significado del arte rupestre esquemático. 


\section{LAS INVESTIGACIONES EN EL NÚCLEO DE LA SIERRA DE QUESADA}

Fue a partir de 1984 cuando, estimulados por la idea de que el vacio de localización de yacimientos con arte rupestre existente entre los núcleos de Sierra Morena y de Sierra Mágina, por un lado, y los de Nerpio y del Sureste en general, por otro, pudiera deberse a un vacío de investigación, asumimos como objetivo la prospección de la amplia barrera montañosa que las Sierras Subbéticas forman en la región nororiental de la Alta Andalucía.

Tal tarea fue facilitada en la Sierra de Quesada por la inestimable colaboración de un grupo de amigos, entre los que sobresale Manuel Vallejo Laso, cuya labor de prospección abrió el camino a nuestros trabajos de investigación. En esta zona realizamos cinco campañas de trabajo, efectuadas durante los años 1984, 1985, 1990, 1992 y 1995, las tres últimas dentro de un proyecto aprobado por la Dirección General de Bienes Culturales de la Junta de Andalucía, que pusieron al descubierto la existencia de un núcleo rupestre integrado por doce yacimientos que contenían pinturas levantinas y grabados y pinturas de estilo esquemático.

Efectivamente, en las campañas de 1984 y 1985 realizamos el estudio de cuatro abrigos con pinturas, bautizados con los nombres de Cueva del Encajero, Abrigo del Cerro Vítar, Cueva de la Hiedra y Cueva Cabrera, y de una serie de hallazgos arqueológicos superficiales que sirvieron para documentar, de forma provisional, el poblamiento arqueológico de la zona (Soria Lerma, López Payer, Vallejo y Peña, 1987; Soria Lerma y López Payer, 1989, págs. 93-100).

En la tercera campaña, efectuada entre los meses de marzo y julio de 1990 , procedimos al estudio de los conjuntos denominados Abrigo de M. Vallejo, Abrigos del Vadillo I y II, Abrigo del Arroyo de Tíscar y Cueva del Reloj, que vinieron a confirmar de manera definitiva el desarrollo de los estilos postpaleolíticos en este núcleo. Los resultados de esta campaña fueron presentados en las IV Jornadas de Arqueología Andaluza (López Payer y Soria Lerma, 1992; Soria Lerma y López Payer, 1992).

Posteriormente, en la campaña que realizamos en 1992, estudiamos los yacimientos de Abrigo del Melgar, Cueva de Clarillo y Cueva de La Troje, los dos primeros de una importancia transcendental para la comprensión del fenómeno rupestre en el Sureste. En el caso de la Cueva de Clarillo, efectuamos el insólito hallazgo de varias manos impresas, únicas por el momento en el arte postpaleolítico peninsular.

Finalmente, en octubre de 1995, realizamos otra campaña de trabajo en las cercanías de los yacimientos anteriores, documentando diversas figu- 


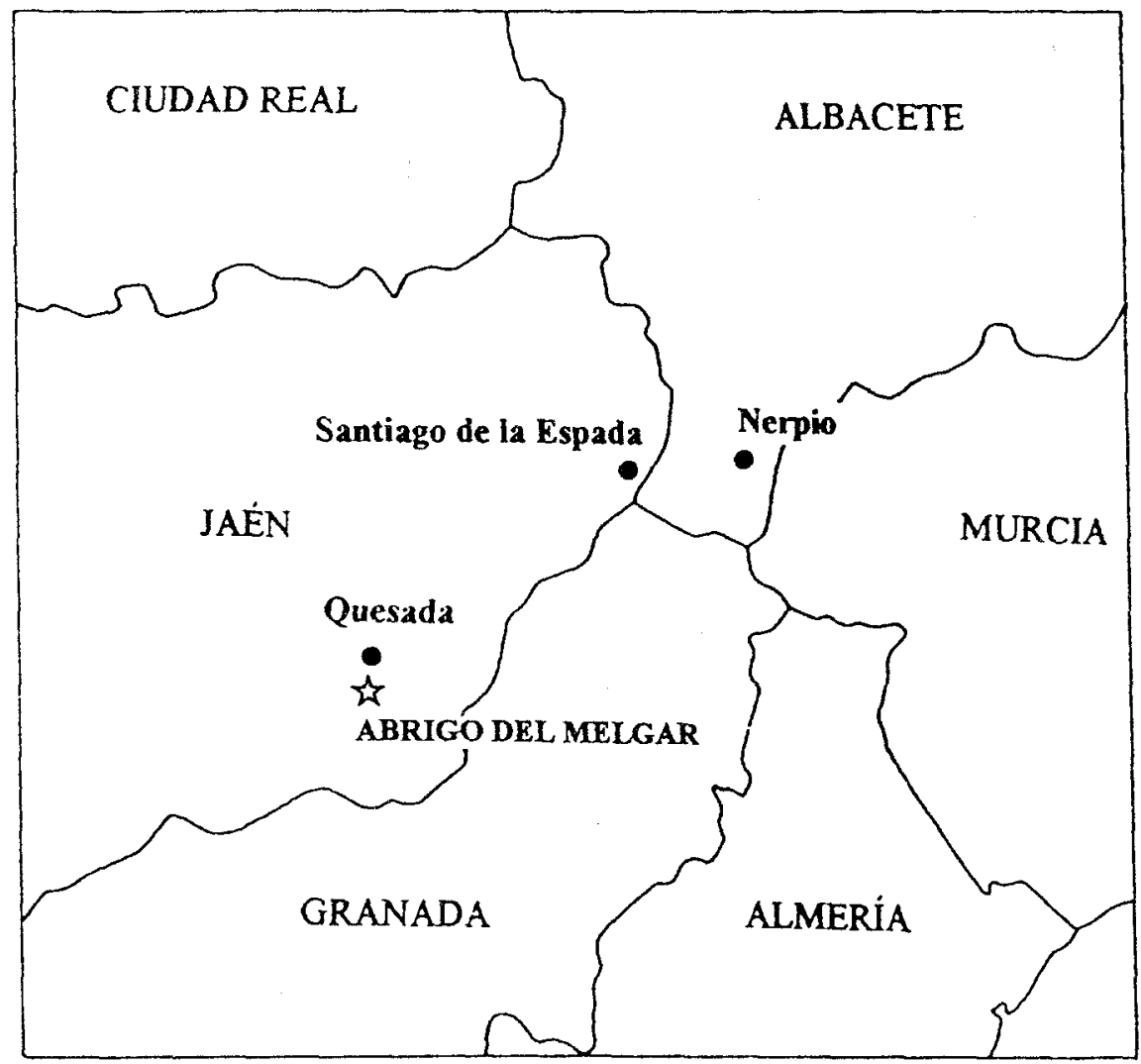

Fig. 1. Localización del Abrigo del Melgar en el sureste peninsular.

ras esquemáticas en una serie de abrigos que bautizamos como Abrigos de los Niños.

Como ya hemos indicado, uno de los conjuntos inéditos hasta la fecha es el del Abrigo del Melgar. A él nos referimos a continuación.

\section{DESCRIPCIÓN DEL YACIMIENTO}

Este conjunto fue descubierto por Manuel Vallejo Laso en una pequeña oquedad ubicada en los promontorios rocosos situados en las estribaciones nororientales de la mole caliza del Cerro Vítar, en la zona de la que toma su nombre. 


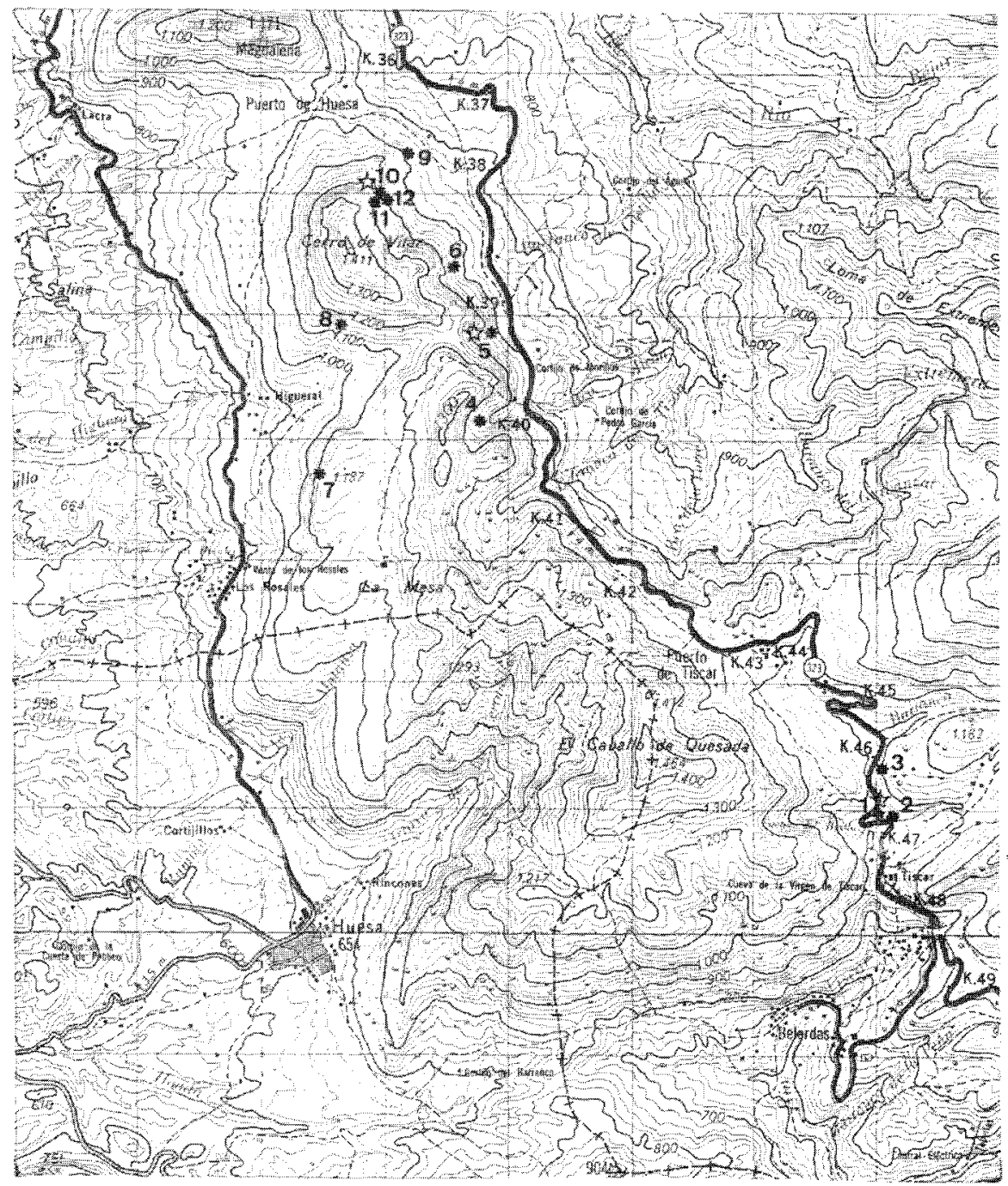

Fig. 2. Mapa de situación de los yacimientos rupestres del Núcleo de Quesada.
1. Abrigo de M. Vallejo.
3. Abrigo del Arroyo de Tíscar.
5. Cueva del Encajero.
7. Cueva de la Hiedra.
9. Abrigo del Melgar.
11. Cueva de la Troje.

2. Abrigos I y II del Vadillo.

4. Cueva del Reloj.

6. Abrigo del Cerro Vítar.

8. Cueva Cabrera.

10. Cueva de Clarillo.

12. Abrigos de los Niños.

Abrigos que también contienen grabados. 

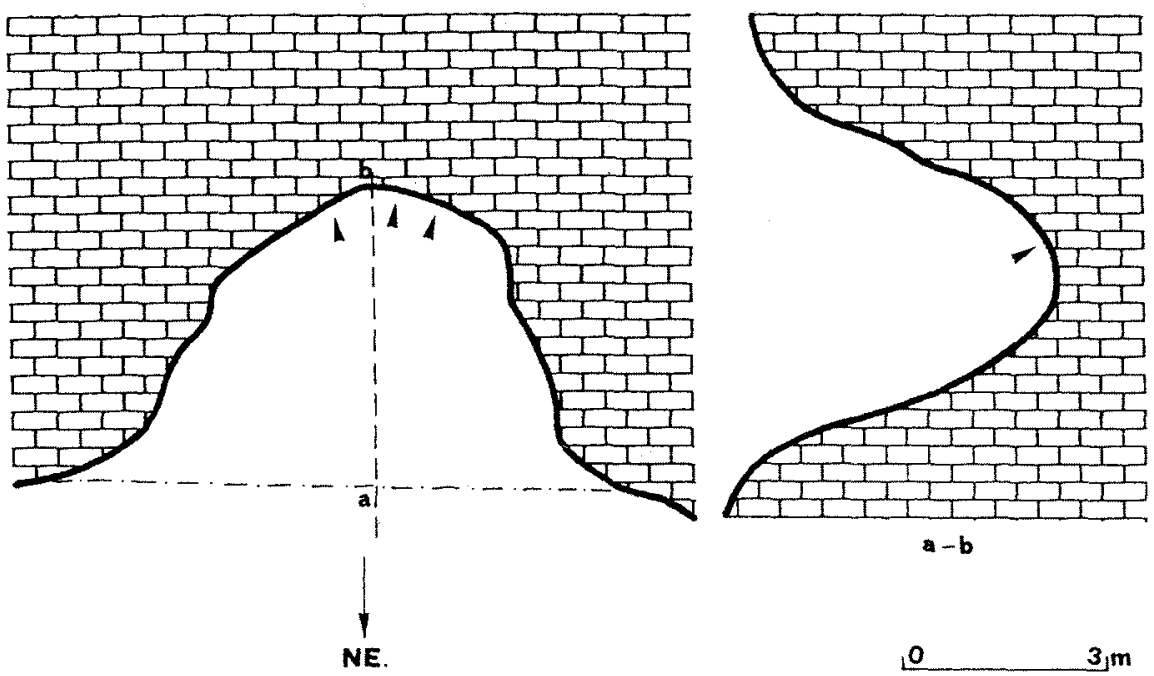

Fig. 3. Abrigo del Melgar.

El covacho tiene unas dimensiones reducidas: $3 \mathrm{~m}$. de anchura, $2 \mathrm{~m}$. de profundidad y $2 \mathrm{~m}$. de altura; está orientado al N.E. y a unos $960 \mathrm{~m}$. de altitud.

Las pinturas se encuentran distribuidas por los pequeños alisamientos que la pared rocosa forma en el fondo del abrigo $y$, aunque su conservación no es buena, su color, rojo carmín oscuro, les hace destacar sobre el color claro de la roca soporte. En total hay unas 27 figuras: 22 bitriangulares; 2 zoomorfos, uno del subtipo cáprido y otro pectiniforme; un ramiforme vertical; una barra; restos de otras figuras situadas en la parte inferior, posiblemente bitriangulares, y una figura mal conservada, ubicada en el extremo superior de la derecha, que pudo ser, a juzgar por lo que de ella se conserva, un oculado o una figura similar.

Todas las figuras son de pequeño tamaño -la mayor tiene 3 ' $5 \mathrm{~cm}$. de longitud y la menor $1^{\prime} 5 \mathrm{~cm}$. - y se realizaron con una técnica de trazo fino, continuo y del mismo espesor -entre 2 y $3 \mathrm{~mm}$.-, que en el caso de los bitriangulares sirvió para delimitar las figuras dejando el interior sin ningún tipo de relleno.

El estilo es típicamente esquemático, habiendo sido reducidos todos los motivos, mediante sus líneas básicas e imprescindibles, a sus elementos más significativos. Mientras los antropomorfos están representados frontalmente, los zoomorfos lo están de perfil, excepto el detalle de la cuerna de uno de ellos, que aparece en perspectiva semitorcida. 
En un primer análisis de distribución espacial, observamos la presencia de dos grupos de cuatro miembros cada uno, compuestos por dos bitriangulares grandes y dos pequeños, que se alternan entre sí y que, en nuestra opinión, aluden a la representanción de dos grupos familiares. Hay también una marcada tendencia a agrupar el resto de los antropomorfos de dos en dos, mientras que el posible oculado parece dominar el conjunto desde la derecha.

Aparentemente, si excluimos la representación casi en horizontal de los referidos grupos familiares, no hay indicios de registros horizontales o verticales de las figuras, lo que no quiere decir que estén distribuidas al azar, pues se observa una intencionada asociación de figuras bitriangulares con figuras zoomorfas y simbólicas.

\section{SIGNIFICADO Y PARALELISMOS}

Por todos es conocida la enorme dificultad que siempre ha representado el intentar profundizar en el análisis del significado de los conjuntos de estilo esquemático, por ser éste un estilo más dirigido hacia la expresión de la idea que preocupado por la forma. A esta dificultad, normalmente, se le han añadido otras aportadas por el bagaje de prejuicios que el propio investigador se ha formado sobre dicho estilo. Uno de ellos se refiere a la contraposición tradicional entre el caracter narrativo del estilo levantino y el caracter conceptual propio del esquemático, conclusión que ha sido obtenida a partir de la simple observación de las composiciones escénicas del primero y de la falta, entre otros factores, de un registro de ordenamiento en el segundo. Nosotros pensamos que para los autores de las pinturas esquemáticas es muy posible que las composiciones escénicas se basaran, en la mayoría de los casos, en las asociaciones de unas figuras con otras. En consecuencia creemos que el primer paso, aunque no el único, que podemos dar para analizar el significado de conjuntos como éste del Melgar, es estudiar las asociaciones de las figuras que en él aparecen y sus paralelismos.

Comenzando por las figuras bitriangulares, que son las más representativas del conjunto, el análisis de la distribución peninsular de estos motivos (Acosta, 1968, mapa 12, pág. 208), nos indica que su principal área de difusión se localiza en los núcleos de las sierras de Almería, en la zona gaditana y especialmente en Sierra Morena, en el tramo comprendido entre las provincias de Jaén y Badajoz, ambas incluidas.

En la zona almeriense, en el núcleo de la Sierra de los Filabres, estas figuras aparecen en el conjunto II de la Roca del Almendral, denominado 


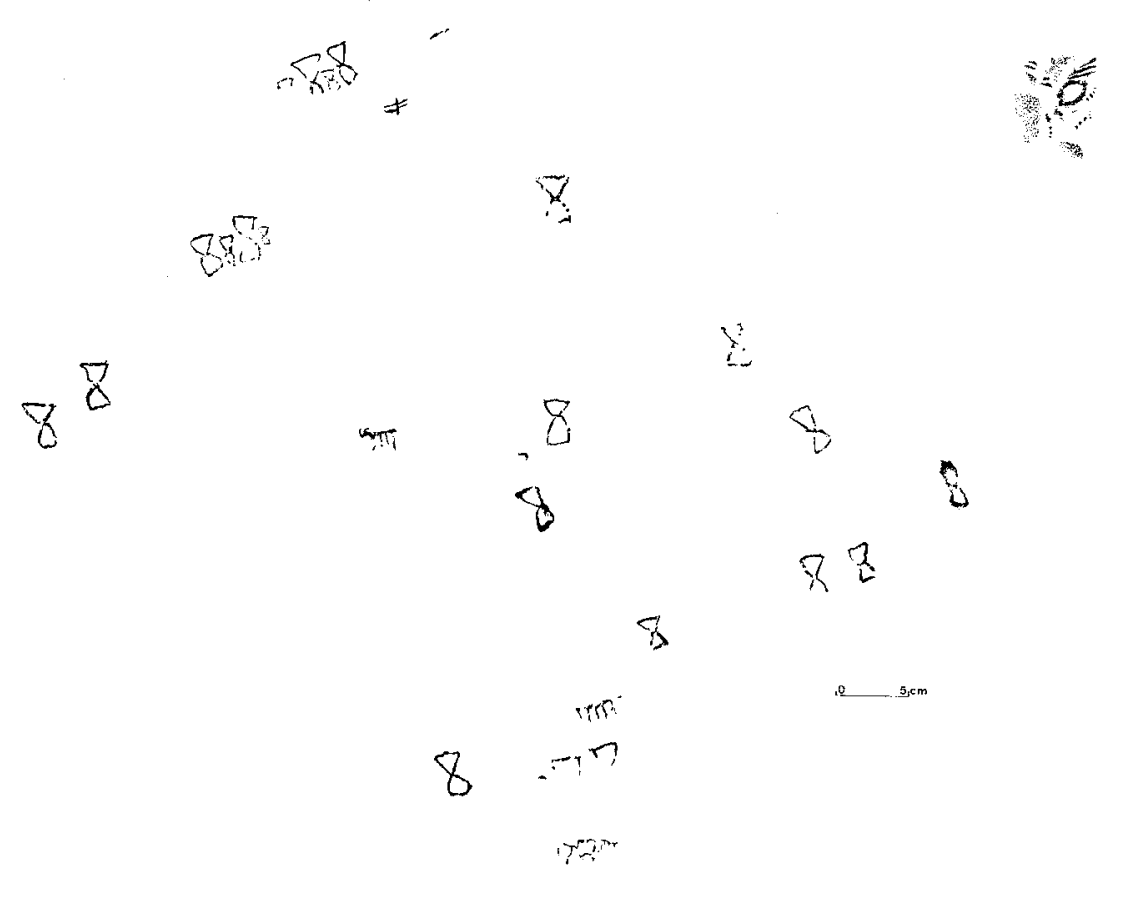

Fig. 4. Abrigo del Melgar.

también Peñón de las Juntas (Breuil, 1935, pág. 44; Martínez, 1981, pág. 42), donde observamos la presencia de dos bitriangulares con eje central que están asociados a antropomorfos de brazos en asa, ramiformes y barras.

En el núcleo Norte de Almería, el yacimiento con bitriangulares de mayor importancia es el de la Cueva de los Letreros, lugar donde aparecen en gran número, entrelazados y en sucesivos niveles, como si se tratara de la representación de un árbol genealógico (Breuil, 1935, págs. 9-17; Soria Lerma y López Payer, 1989, págs. 34-35, lám. 3), o la expresión gráfica de un sistema de parentesco (Martínez, 1992, págs. 183-189). Tanto en este caso como en el Abrigo del Melgar, se evidencia que el esquema bitriangular se utilizó indistintamente para realizar tanto representaciones masculinas como femeninas.

Dentro del mismo núcleo, nos encontramos con un yacimiento con un estrechísimo paralelismo respecto al conjunto del Melgar, nos referimos al Abrigo del Gabar (Breuil, 1935, págs. 27-29, lám. XXIII), cuyo contenido reune por igual aspectos descriptivos y simbólicos, apareciendo una serie de 
bitriangulares técnicamente similares a los del Melgar, que presentan unos tracitos verticales y paralelos en sus extremos superior e inferior. Algunas de estas figuras están unidas horizontalmente formando grupos de dos o tres unidades, mientras que otras aparecen aisladas. Hay también numerosas figuras solares, formando parejas o aisladas, en dos ocasiones unidas a cada lado del extremo superior de una figura bitriangular; un cérvido próximo a cuatro alineaciones en zig-zags, posiblemente representando un curso de agua; un équido en el otro extremo; puntos y un arquero esquemático.

Siguiendo en el mismo núcleo, también encontramos bitriangulares similares a los del Melgar en el Estrecho de Santonge (Breuil, 1935, lám. $X X V, 3)$ y en la Cueva del Queso. Este último yacimiento con dos bitriangulares rodeados de puntos y acompañados de una especie de zoomorfo (Breuil, 1935, pág. 27, lám. XX,2).

Desplazándonos hacia el Norte, en el arco montañoso del Subbético Giennense, este motivo se encuentra escasamente representado, pues además del caso que nos ocupa sólo se halla en el yacimiento de La Cantera, en el Núcleo Sur de Jaén, donde observamos dos bitriangulares muy incompletos, uno de ellos asociado a dos cápridos y a varios puntos (Soria Lerma y López Payer, 1989, lám. 67).

Hacia el área levantina encontramos también una serie de paralelos, no tan abundantes como los citados pero dignos de tener en cuenta, entre los que cabe citar una pareja de bitriangulares de la Cueva del Gitano, ubicada en el Alto Segura (Pérez Burgos, 1996, págs. 15-18; Soria Lerma y López Payer, e.p.); algún ejemplar del Castillo de Taibona, en el núcleo de Nerpio (Alonso y Grimal, 1996, vol. II, fig. 107), y los del Abrigo del Barranc de la Palla en Alicante (Hernández, Ferrer y Catalá, 1988, págs. 222).

Por su parte, en Sierra Morena Oriental estas figuras se presentan con escasa relevancia en Los Arcos y en el Barranco del Bu, y en cierta cantidad en el panel principal de Vacas del Retamoso (López Payer y Soria Lerma, 1988, láms. 18, 49 y 78), lugar donde se asocian a una rica variedad de símbolos, entre los que se encuentran barras, zig-zags, pectiniformes, dientes de lobo, bilobulados, puntos, ramiformes, un oculado y, sobre todo, gran número de soles.

En esta misma zona de Sierra Morena llama también la atención el empleo reiterado del esquema bitriangular en la realización de determinadas figuras con tocado, como es el caso de una figura de La Garganta de la Hoz y de otras del conjunto de Los Organos (López Payer y Soria Lerma, 1988, láms. 30 y 51). En este último lugar se trata de antropomorfos bitriangulares asociados a un cérvido, a una figura oval y a varias barras, que pueden representar un arco y varias flechas, formando una escena relativa a algún rito propiciatorio de la caza del ciervo o de culto a este animal. 

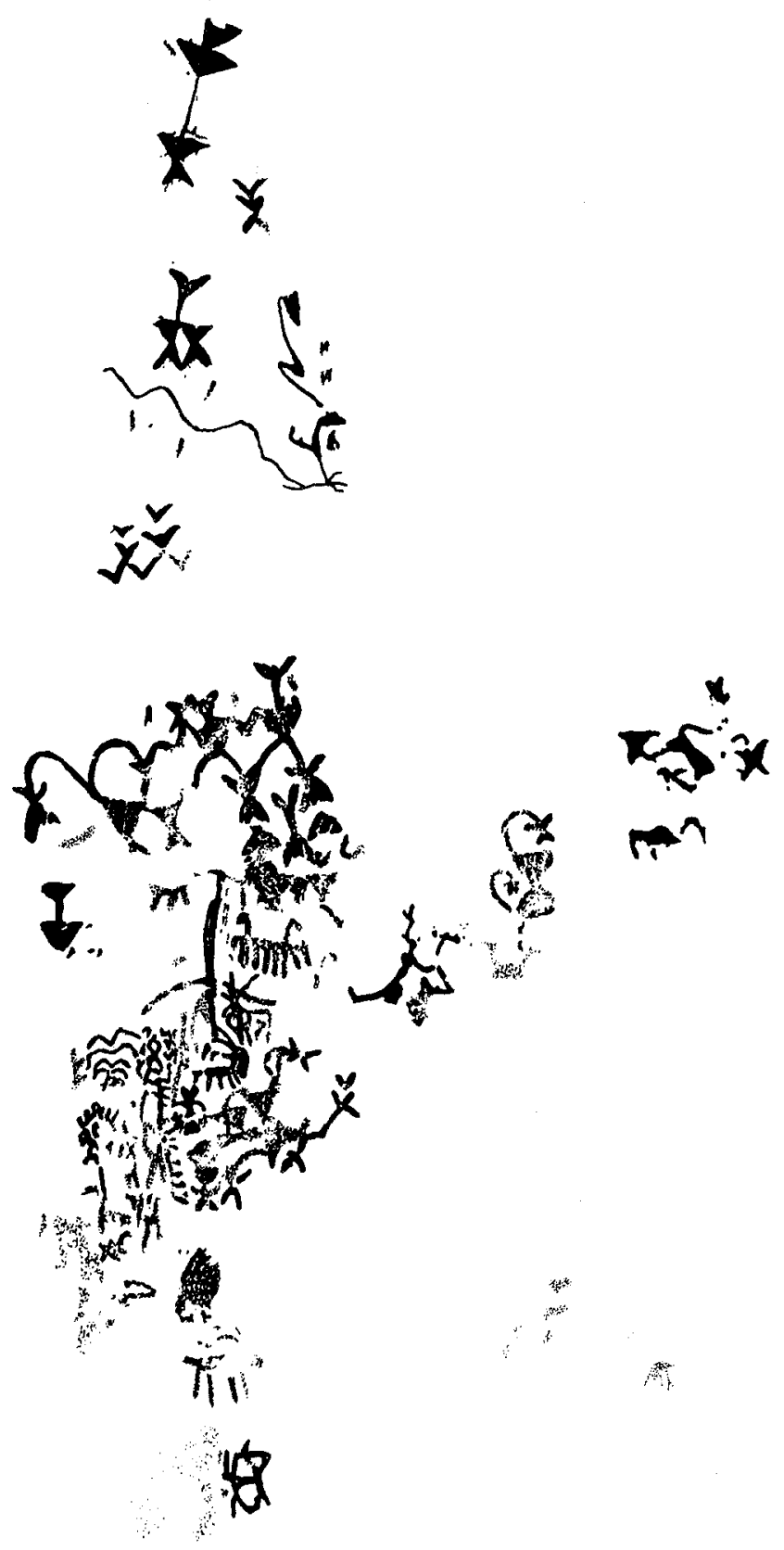

Fig. 5. Detalle del panel principal de la Cueva de los Letreros (Vélez Blanco, Almería). 


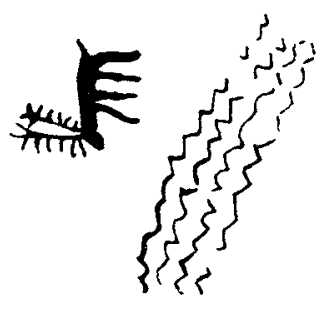

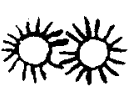

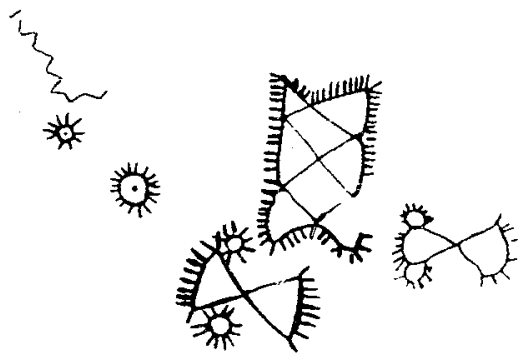

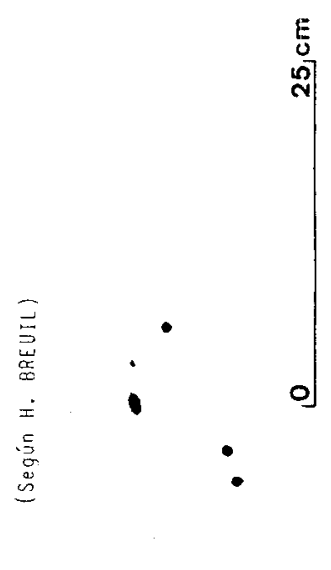

use
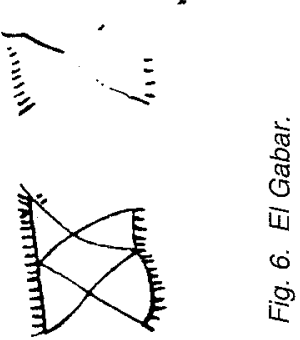

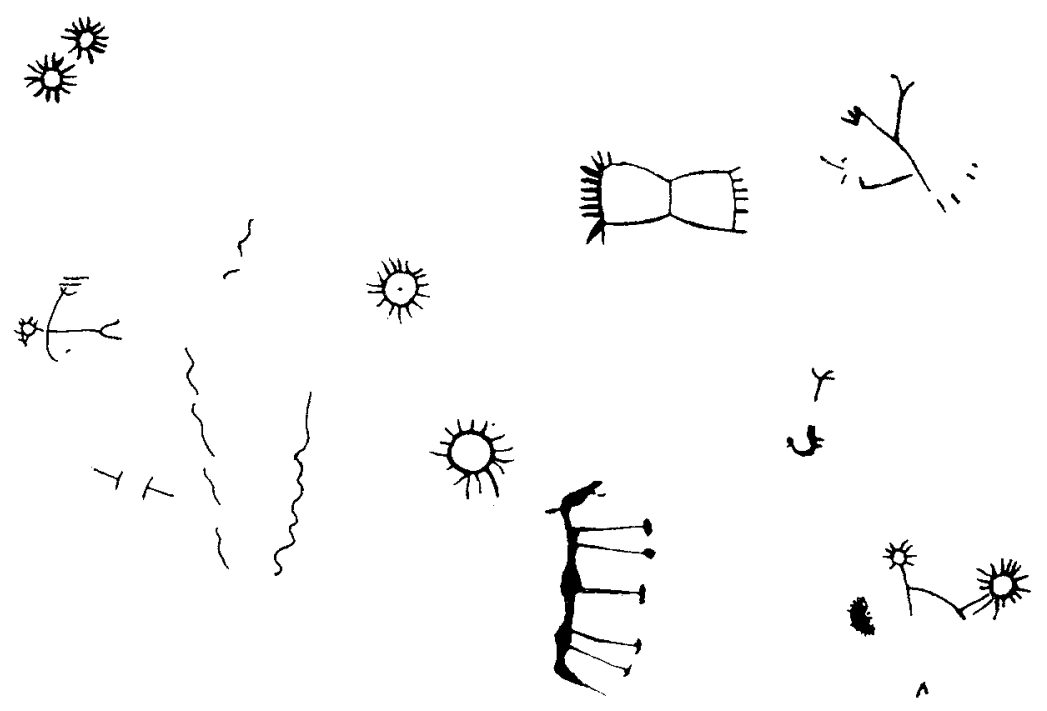


En la vertiente septentrional de Sierra Morena las representaciones bitriangulares alcanzan un número extraordinariamente importante y significativo, estando presentes en bastantes abrigos y en casi todas las variantes posibles, desde el esquema más simple, ya sea relleno de tinta plana o sólo trazado en su contorno, formando grupos, parejas o aislados, y en muchos casos unidos horizontalmente; hasta esquemas con cabeza cuadrangular, con brazos en asa o en arco, con un eje central, con base circular o con cabeza triangular; todas ellas en variantes simples o mezcladas entre sí, tal y como podemos apreciar en conjuntos como los de Cordoneros, La Cornisa, Puerto Palacios, Morrón del Puente, Covatilla de San Juan, Peña Escrita, El Escorialejo, Los Gavilanes, El Monje, Covatilla del Rabanero, Puerto Calero, Collado del Pajonar y Callejones de Río Frío (Caballero, 1983, vol. II). De ello se deduce que en esta zona la aceptación del esquema bitriangular se hizo en toda su plenitud, apreciandose incluso una equivalencia de este motivo con el halteriforme en los yacimientos de Cordoneros, La Cornisa y Covatilla de San Juan (Caballero, 1983, vol. II, pl. 51 y 68, y vol. I, págs. 461-462, 493-496, láms. 9,10, 28-30).

Las asociaciones de figuras en esta zona son igualmente relevantes, apareciendo bitriangulares asociados a un cérvido y un sol en Morrón del Puente; a un zoomorfo pectiniforme en El Escorialejo; a reticulados, ramiformes y barras en Los Gavilanes; a reticulados, barras, pectiniformes, zoomorfos y figuras en phi en Covatilla del Rabanero, y a un ramiforme y un sol en Puerto Calero (Caballero, 1983, pl. 65, 85, 95, 192, 103 y 108).

Hacia la zona de Badajoz aparecen los bitriangulares en menor profusion, pero con las mismas características y tipos de agrupaciones. Tal es el caso de los yacimientos de Moriscas del Helechal y Abrigo Grande de las Viñas, conjuntos en los que se asocian a ramiformes (Breuil, 1933, láms. XXV y XXXI).

Por último, en la zona gaditana vuelven a repetirse estos esquemas en Canuto Ciaque II, Rosa, Mujeres, Carboneros y Palomas IV (Breuil y Burkitt, 1929, láms. XII, XIII y XVIII). En el caso del conjunto de Mujeres, aparecen los bitriangulares con un tocado de círculos o aretes a ambos lados de la cabeza, de forma similar al caso citado de Los Organos en Sierra Morena, estando asociado uno de ellos, en el abrigo gaditano, a un ramiforme.

En cuanto a los dos zoomorfos del Abrigo del Melgar sus características son las típicamente esquemáticas, pudiendo tratarse de cápridos domésticos o salvajes, o de ambas especies. Dada su morfología, el estudio de sus paralelismos y su distribución son escasamente significativos, apareciendo asociados con todo tipo de figuras (Acosta, 1968, mapa n. ${ }^{\circ}$ ). 

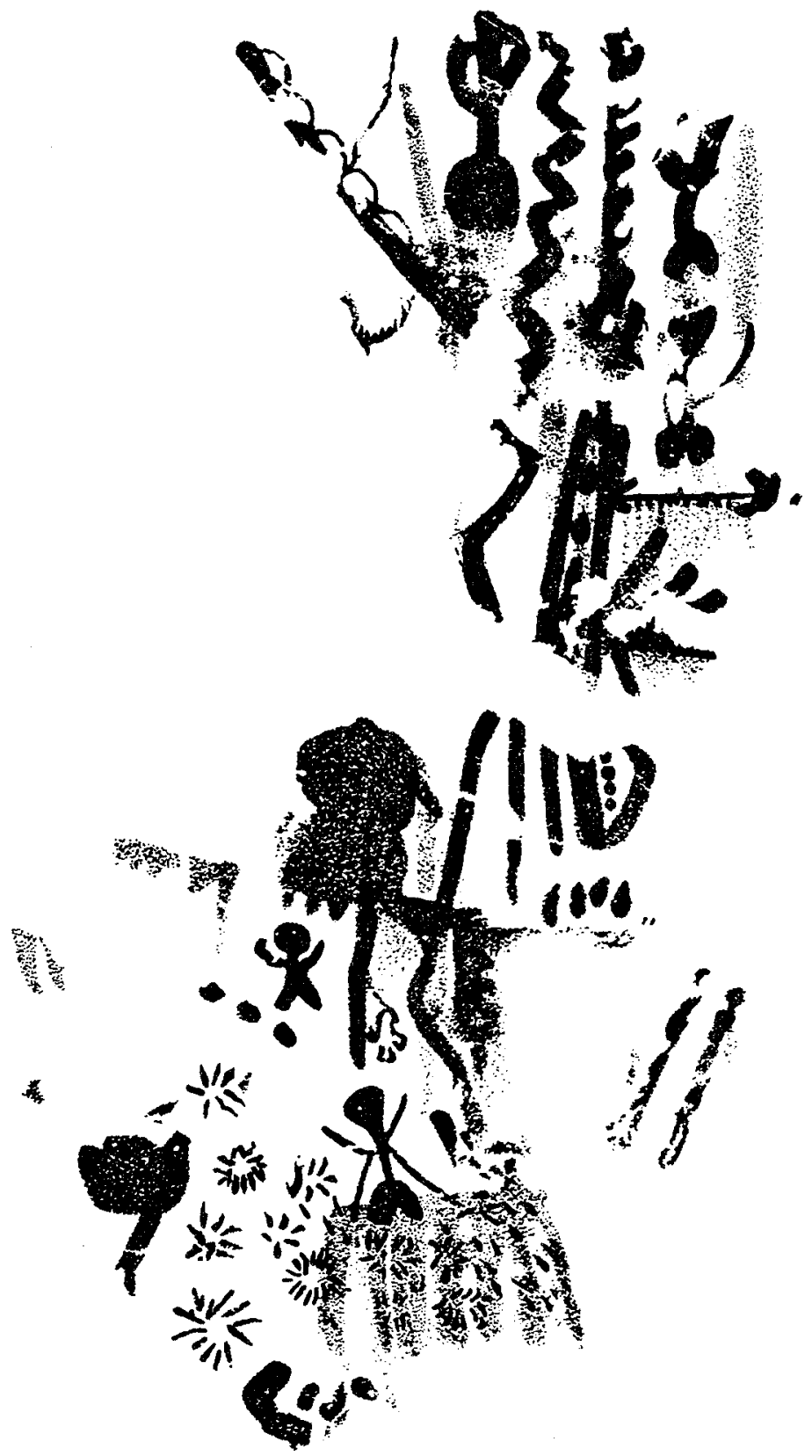

Fig. 7. Detalle del panel principal de Vacas del Retamoso (Santa Elena, Jaén). 
Más relevante, en cuanto al significado, es el análisis de las figuras ramiformes, igualmente distribuidas por toda el área esquemática (Acosta, 1968 , mapa.$^{\circ} 1$ ), las cuales aparecen asociadas a una gran variedad de figuras, especialmente a los bitriangulares, siendo sus casos más representativos los ya reseñados.

Precisamente en un trabajo sobre el núcleo de Quesada, partiendo de los paralelos de este tipo de figuras en el Alto Guadalquivir, lanzamos la hipótesis de que los ramiformes verticales pudieran ser representaciones del árbol generador de vida que, asociado a antropomorfos, sean o no figuras femeninas, y a zoomorfos, estarían relacionados con ritos de culto a la fertilidad, tanto de personas como de animales (Soria Lerma y López Payer, 1992, págs. 76-80). En un trabajo reciente (Soria Lerma y López Payer, 1999, págs. 8-13), llegábamos a la conclusión de que este tipo de figuras podían también aludir a un simbolismo de origen animal, estando ligadas en este caso a las cualidades atribuidas a los cérvidos (fuerza, agilidad, fecundidad...).

Finalmente, en cuanto al posible oculado del Abrigo del Melgar, dado su caracter dudoso, resultaría poco sólida una hipótesis que ignorara esta circunstancia, a pesar de ello, su existencia en este conjunto no sería un hecho anómalo dada la proximidad de este núcleo con otros donde sí están representados oculados con una apariencia similar, es decir, con varios trazos paralelos, más o menos arqueados y situados encima o debajo de los ojos. Nos referimos concretamente a los del Collado del Guijarral y de la Cueva de la Diosa Madre, ambos en el núcleo de la Sierra de Segura (Soria Lerma y López Payer, 1989, págs. 86-92, láms. 47-49) y a los de los abrigos del ídolo y de los ídolos en el núcleo de Nerpio (Alonso y Grimal, 1996, vol. I, págs. 53 ss.). En el caso del Collado del Guijarral aparecen asociados con figuras de arqueros, cánidos y una serie de motivos simbólicos como bilobulados, figuras en $\mathrm{V}$ y ramiformes horizontales.

Por todo lo expuesto, de la observación de las asociaciones de figuras, parece desprenderse que la asociación antropomorfo-zoomorfo-símbolo, representada en el caso que nos ocupa por la relación bitriangular-cáprido/pectiniforme-ramiforme, a la que se podría unir el posible oculado, es extremadamente abundante si pensamos en sus posibles equivalentes: bitriangulares-zoomorfos (cáprido, cérvido, cuadrúpedo, pectiniforme)-símbolos (sol, ramiforme, oculado), tal y como ha quedado bien patente en los yacimientos ya referidos, de los que es claramente representativo el conjunto del Gabar, donde se asocian bitriangulares con zoomorfos y soles, y en el que la identificación ojos-soles aparece en dos de las figuras, circunstancia que no es casual, produciendose la misma identificación 
en materiales muebles de la Edad del Cobre, caso de las cerámicas simbólicas de Los Millares, donde además se repite el mismo tipo de asociación (Siret, 1906-1907) (Martín Socas y Camalich, 1982, págs. 267-306).

Hay que pensar, por consiguiente, respecto de las asociaciones citadas, que no se trata de meras coincidencias, sino de un lenguaje concreto que se sirve de los mismos signos o de signos equivalentes y que responde a un mismo objetivo y significado. Un significado que, como se refleja en el Abrigo del Melgar, viene a ser el exponente de la preferencia por los esquemas bitriangulares para las figuras humanas cuando se trata de expresar relaciones de tipo social, familiar o conyugal y que, cuando se asocian a ramiformes, responden muy probablemente a representaciones de ritos de culto a la fertilidad. En consecuencia, se trataría, en nuestro caso, de una configuración del propio universo existencial de los autores de las pinturas y de su deseo de perpetuar la vida humana, representándolo a través de los grupos sociales, de sus medios de subsistencia y de las figuras simbólicas que aludían a los ritos que favorecían su perpetuidad. De esta forma, los grupos sociales estarían representados por los motivos bitriangulares, ya sea constituyendo grupos familiares, parejas o simples individuos; mientras que los medios de subsistencia lo estarían por el cáprido y el zoomorfo pectiniforme, que aludirían a la caza o a la ganadería como medios para procurarse el sustento alimenticio, y las figuras simbólicas por el ramiforme y el posible oculado, claros exponentes de un determinado tipo de cultos que, en el caso de los ramiformes estarían posiblemente vinculados a ritos de fecundidad, y en el caso de los oculados, pudieran estar relacionados con un simbolismo similar o con una deidad protectora de gran implantación entre las poblaciones prehistóricas peninsulares en los periodos anteriores a la Edad del Bronce, cuyo mejor exponente lo encontramos en los ídolos oculados aparecidos en arte mueble, tanto en huesos decorados como en las llamadas cerámicas simbolicas, la mayoría de ellos aparecidos en el Sureste y Levante y a los que posteriormente aludiremos.

\section{CRONOLOGIA Y CONCLUSIONES}

Las peculiares características tipológicas del conjunto del Melgar hacen que, en principio, resulte relativamente cómodo abordar el problema de su cronología, sobre todo si pensamos en la existencia de gran cantidad de paralelos de sus figuras con otras del arte mueble, algunas de ellas fechadas con métodos absolutos. Otro problema es tratar de precisar la cronología de este conjunto dentro de su núcleo, dados los escasos datos 
que poseemos sobre el poblamiento prehistórico de la zona y su caracter exclusivo dentro de su entorno.

Comenzando por los paralelos en arte mueble de las figuras bitriangulares, hay que aludir a los llamados ídolos cruciformes, ejecutados generalmente en hueso o en piedra con indicación de los dos triángulos, a los que a veces se les añade un apéndice cuadrangular para indicar la cabeza, o dos apéndices laterales a modo de brazos. Su morfología responde exactamente a la reflejada en las pinturas. De estos ídolos cruciformes distingue M. ${ }^{\text {a }} \mathrm{J}$. Almagro siete variantes, que vienen a responder a un esquema similar, cuya distribución geográfica se centra principalmente en el Sureste, especialmente en la provincia de Almería, decreciendo su densidad hacia las provincias de Granada y Jaén por un lado, y hacia Murcia y Alicante por otro. También aparecen ejemplares en Huelva y en la zona de Lisboa (M. ${ }^{a} \mathrm{~J}$. Almagro, 1973, págs. 33-62, mapa 2).

La mayoría de estas figuras se han catalogado como pertenecientes a la Edad del Cobre, si bien la primera fechación que se posee para las figuras bitriangulares procede de un hallazgo de cerámica incisa, decorada con este motivo, procedente del Estrato VI, Area G de La Carigüela, que fue fechado en el Neolítico Final (Acosta, 1984, pág. 39). Sin embargo, la fecha más conocida procede de la datación absoluta de los vasos de Los Millares, ya citados con anterioridad, situada hacia el $2345 \pm 80$ a.C. (M. Almagro, 1959, págs. 249-251). No obstante, el abanico cronológico podría llegar hasta el 1800 a.C. aproximadamente, según los datos aportados por el hallazgo de un bitriangular en piedra en los niveles de transición de la Edad del Cobre con El Argar del yacimiento de La Carigüela (Pellicer, 1964, págs. 30 ss.).

En cuanto al probable oculado del Melgar, sus paralelos en arte mueble son los también denominados ídolos oculados, realizados en hueso, piedra y cerámica (M. ${ }^{a}$ J. Almagro, 1973, págs. 134-180). Los realizados en piedra tienen su principal área de dispersión por Extremadura, Andalucía Occidental y el Alentejo. Por su parte, los realizados sobre hueso tienen su principal área de dispersión en el Sureste, siendo los ejemplares más conocidos los de La Pastora (Alcoy), Ereta del Pedregal (Valencia), Malla Verda (Corbera de Alcira), Bolumini (Alfarara, Alicante), Garrofer (Onteniente) y Almizaraque en Almería, algunos de ellos aparecidos en contextos funerarios. Su cronología se corresponde básicamente con la Edad del Cobre, siendo válida para este motivo la datación absoluta ya citada de los vasos de Los Millares, decorados, como ya sabemos, con las figuras de ojos-soles.

Respecto a los zoomorfos esquemáticos del Melgar, sus paralelos en arte mueble se encuentran generalmente en motivos incisos realizados en 
El Abrigo del Melgar. Nuevas apreciaciones cronológicas sobre las pinturas...

cerámica, cuyo abanico cultural va desde el Neolítico hasta el Campaniforme (Acosta, 1984, pág. 38). Algo similar sucede con los ramiformes, de los que encontramos motivos incisos en cerámica desde el Neolítico Medio y Final hasta el Bronce (Acosta, 1984, págs. 37 y 38).

En lo que se refiere al poblamiento prehistórico de la zona suceptible de ser relacionado cronológicamente con las pinturas, ya reseñamos en dos trabajos anteriores sus peculiares características en cuanto a la escasez de datos disponibles y a la dificultad añadida por el hecho de que la mayoría de los hallazgos eran superficiales o aportaban una datación relativa. La excepción a esta tónica general está representada por varios yacimientos ubicados en la Sierra de Segura, donde constituye una suerte para el cometido que nos ocupa el hecho de albergar tres yacimientos excavados sistemáticamente, que pueden arrojar bastante luz sobre el mundo cultural y material que envolvió a los autores de las pinturas postpaleolíticas de la zona. Nos referimos a los yacimientos de la Cueva del Nacimiento, Valdecuevas y Molino del Vadico.

En lo que respecta a la Cueva del Nacimiento (Rodríguez, 1979) (Asquerino y López, 1981), su excavación reveló la presencia de cuatro fases de habitación: la primera, a finales del Paleolítico Superior, datada en torno al 9250 a.C.; la segunda, epipaleolítica, con industria lítica de geométricos y microláminas, fechada hacia el 5670 a.C.; la tercera, en el Neolítico Medio, con industria de silex de tradición epipaleolítica, cerámicas impresas e incisas, con decoración plástica aplicada e incluso pintada, en las que estaba ausente el tipo cardial, y fauna doméstica y salvaje, con dos dataciones, una más antigua (4380 a.C.), aportada por G. Rodríguez, y otra, más reciente (3540 a.C.), aportada por Asquerino y López, que pueden constituir los límites superior e inferior de dicho período, y una cuarta fase, calificada como perteneciente a un Neolítico Final avanzado, con cerámica lisa, en la que predominaba la fauna doméstica sobre la salvaje, que arrojó una datación bastante posterior a las anteriores (2040 a.C.) y que, al ser la más superficial y estar muy afectada por las extracciones de estiércol, nos presenta unos datos que hay que tomar con cierta reserva. Llama la atención el hecho de que en el análisis polínico no aparecieron pólenes de cereales (Asquerino, 1984, págs. 31-40).

Por su parte, el yacimiento de Valdecuevas arrojó una estratigrafía muy similar al anterior, con cuatro fases de ocupación, las tres primeras coincidentes con las de Nacimiento, y una cuarta con niveles eneolíticos (Sarrión, 1980).

En lo que respecta al yacimiento del Molino del Vadico (Córdoba de Oya y Vega, 1988, págs. 79-85), arrojó también una estratigrafía seme- 
jante a la de Nacimiento, con unos primeros niveles de ocupación en el Paleolítico Superior Final; seguidos de otros correspondientes a niveles epipaleolíticos de facies laminar, con fauna salvaje (cabra, conejo y en menor cuantía el ciervo), y una fase neolítica con cerámicas impresas e incisas, industria lítica y, según noticias que recogen A. Alonso y Grimal (1996, vol. II, págs. 262 y 263), restos de grano.

Globalmente, se observa en estos yacimientos que la caza, sobre todo del ciervo, la cabra montés, el rebeco, el corzo y el jabalí, fue muy importante para la dieta alimenticia de sus pobladores, si bien se aprecian ciertas diferencias, pues mientras en Valdecuevas el animal más cazado es la cabra montés, quizás porque el nicho ecológico del yacimiento es más adecuado a ésta, en Nacimiento el animal más cazado es el ciervo. A partir del Neolítico Medio se introdujo la domesticación de ovicápridos, aunque la caza siguió siendo la actividad principal en Nacimiento, mientras que en Valdecuevas, en este período, la fauna doméstica supera ligeramente a la salvaje.

Además de los datos aportados por las excavaciones de estos yacimientos, los resultados obtenidos por la realización de varias prospecciones superficiales efectuadas en la zona por G. Rodríguez (1997), nos muestran la existencia de un importante poblamiento en torno a los ríos Segura, Zumeta y Río Frío, que tiene sus raices en el Paleolítico Superior y que se acentúa en el Epipaleolítico y en el Neolítico, evidenciando, según su investigador, cómo las últimas poblaciones cazadoras aceptaron, inicialmente y mediante un proceso de aculturación, tan sólo aquellos elementos propios de la economía de producción, como la ganadería y el uso de la cerámica, que suponían una mejora de sus condiciones de vida, pero que no alteraban sus actividades tradicionales en un grado sustancial, ya que la abudancia de caza hacía innecesaria la adopción de una economia cerealista que hubiera supuesto un cambio más profundo en sus hábitos cotidianos y una mayor inversión de trabajo.

En el entorno de los yacimientos citados, también fueron encontrados una serie de materiales procedentes de un enterramiento ubicado en un abrigo natural próximo al Río Frío, entre los cuales, además de diverso material lítico, se hallaron un punzón, una cuenta de cobre, una placa de arquero y un fragmento de cerámica campaniforme, que fueron catalogados como pertenecientes a una fase de finales del III milenio o principios del II a.C. (Carrasco, 1980, págs. 86-88).

En el mismo núcleo serrano se ubica el yacimiento de Hornos de Segura (Maluquer, 1975, págs. 287-305), cuya excavación arrojó unos datos que nos permiten enlazar con los períodos reflejados en los yacimientos 
citados. En él se observaron cuatro fases de ocupación: la primera, correspondiente al Neolítico Final-Eneolítico, con cerámicas incisas y decoradas que representan tradiciones neolíticas anteriores; la segunda, con cerámicas lisas propias del Eneolítico; una tercera con cerámica campaniforme y, por último, una cuarta fase correspondiente al Argar B.

Todos estos datos vienen a confirmar la existencia de un fuerte poblamiento en la Sierra de Segura durante los períodos correspondientes al Mesolítico y al Neolítico, así como el hecho de que las tradiciones culturales epipaleolíticas se mantuvieron intensamente arraigadas por lo menos hasta el Neolítico Medio.

Ya en la Sierra de Quesada, adyacente con las del Pozo, Cazorla y Segura, el panorama arqueológico se circunscribe al que nosotros mismos analizamos en otra ocasión (Soria Lerma, López Payer, Vallejo y Peña, 1987, págs. 26-44). En él dábamos cuenta de una serie de hallazgos pertenecientes a la Edad del Cobre, entre los que se encontraban diversos materiales líticos (azuelas, hojas de silex), oseos (punzones, espátulas...) y cerámicos (fuentes carenadas, cuencos con mamelones, cuencos semiesféricos...), procedentes de las cuevas de La Hiedra y de La Cornisa y de la zona del Retamal. Posiblemente dentro de la Edad del Cobre tuvo lugar la construcción del sepulcro megalítico del dolmen de La Sabina, ubicado dentro del término de Quesada pero en las proximidades del Guadiana Menor (Zafra y Pérez Bareas, 1995). Esta fase fue seguida de otra de gran implantación, el Argar B, representada por los materiales procedentes de las excavaciones del Corral de Quiñones, y por otros, generalmente fragmentos de vasos carenados y ollas, encontrados en las cuevas citadas y en zonas como el Cortijo del Roto y la Dehesa de Pelos. La cronología para la primera fase se extendería desde principios del III milenio hasta el 1500-1600 a.C., fecha en la que debió iniciarse la fase argárica de Quesada. A falta de datos aportados por excavaciones sistemáticas, podemos indicar, de un modo provisional, que, mientras que los materiales de la primera fase, entre los que destacan las fuentes carenadas de La Hiedra, nos muestran ciertas influencias procedentes del Guadalquivir; los de la segunda, desvelan influencias procedentes del Sureste, respondiendo el tipo y lugar de sus asentamientos a la necesidad de controlar las comunicaciones entre el Alto Guadalquivir y la citada zona.

A la vista de los datos aportados por el poblamiento prehistórico de la zona y por los paralelos en arte mueble, sobre todo de los bitriangulares y del posible oculado, parece razonable pensar que el conjunto del Abrigo del Melgar fuera realizado dentro del período cronológico correspondiente a la Edad del Cobre; todo ello sin menoscabo de que incluso en esas 
fechas, tal y como se deduce de los datos aportados por el poblamiento prehistórico, hubiera también en estas sierras una fuerte pervivencia y preeminencia de las actividades cinegéticas y pastoriles sobre las agrícolas, lo que parece estar en consonancia con lo que el mismo conjunto de pinturas nos revela a través de la presencia de los zoomorfos ya referidos.

La hipótesis cronológica establecida nos conduce, en consecuencia, a rectificar otra expuesta en una ocasión anterior sobre las pinturas de la zona, donde indicábamos, ante la ausencia, entonces, de motivos como los bitriangulares, los oculados o los soles tipo Sureste, que la plasmación de los conjuntos esquemáticos de Quesada pudo realizarse en un momento ligeramente anterior al desarrollo de la fase plena de la Edad del Cobre en el Alto Guadalquivir y quizás como producto de una expansión cultural procedente de la zona de Sierra Morena (Soria y López Payer, 1992, pág. 83). Es evidente que el descubrimiento de este conjunto obliga a modificar dicha hipótesis. Por consiguiente, y teniendo en cuenta, por un lado, que en el Alto Guadalquivir, a juzgar por los datos que hasta el momento se poseen, la Edad del Cobre debió extenderse desde los primeros siglos del III milenio a.C. hasta el periodo del Argar B, aproximadamente hacia mediadios del II milenio a.C., y por otro, la cronología absoluta de los vasos de Los Millares, es muy probable que el conjunto del Melgar se realizara a mediados del III milenio a.C., quizás en un momento posterior al del inicio de la fase esquemática de la Sierra de Quesada, dada la relación de algunos de los motivos esquemáticos con otros correspondientes a las fases finales de desarrollo del estilo levantino.

Otro problema a tratar es el relativo al origen iconográfico de este conjunto, a cuyo respecto puede ser relevante la observación comparada de la distribución geográfica de los motivos bitriangulares en arte mueble y en arte rupestre (M. ${ }^{a}$ J. Almagro, 1973, mapa 2, pág. 134)(Acosta, 1968, mapa 12, pág. 208). De esta observación se deduce que la relación entre yacimientos con motivos bitriangulares en arte mueble y en arte rupestre es claramente favorable a los primeros respecto a los segundos en la zona almeriense; que dicha relación se equipara en el Subbético Giennense, con dos abrigos pintados con este motivo, el del Melgar y el de La Cantera y un único hallazgo de ídolo cruciforme en el yacimiento de Fuente de las Víboras (Cabra del Santo Cristo, Jaén), y que, finalmente, a partir de Sierra Morena, y concretamente desde el núcleo de Despeñaperros y por toda su vertiente septentrional, la relación es infinitamente desproporcionada a favor de los motivos pintados, pues no ha aparecido allí, hasta el momento, ningún bitriangular en arte mueble, mientras que el número de representaciones pintadas es extraordinario. Estos datos podrian conducirnos a pensar que el origen de este motivo estuviera en la zona almeriense, donde con 
toda probabilidad convivieron al mismo tiempo sus manifestaciones en arte mueble y en arte rupestre. Posiblemente desde allí, tras la asimilación del motivo dentro del bagaje de signos del arte rupestre esquemático, se transmitió hacia Sierra Morena a través del pasillo de Pozo Alcón o del Guadiana Menor, siendo el yacimiento del Melgar, por su proximidad a esta vía de comunicación, el exponente más significativo de este hecho. De esta forma se explicaría también la extraordinaria similitud entre este abrigo y el del Gabar.

En Sierra Morena este motivo pudo tener una larga perduración en el arte rupestre esquemático, siendo muy probable, ante su ausencia en el arte mueble, que el papel que correspondiera a éstos en los ritos de aquellas poblaciones, pudiera haberse sustituido plenamente por el que jugaran sus representaciones equivalentes en los abrigos pintados.

Todo esto no es obstáculo para que el mismo núcleo de Quesada recibiera a su vez influencias culturales provenientes de Sierra Morena, anteriores o posteriores a la época en la que se plasmó el conjunto del Melgar, como puede observarse en algunos motivos como los del Abrigo del Cerro Vítar (Soria y López Payer, 1992, págs. 76-83).

En resumen, podemos decir que el Abrigo del Melgar supone la definitiva constatación de una fase pictórica en el núcleo de Quesada claramente datada, por comparación con materiales muebles, dentro del III milenio a.C. Por otra parte, sus figuras muestran una morfología, una técnica y un estilo estrechamente relacionados con el yacimiento de El Gabar (Vélez Blanco, Almería), lo que convierte a nuestro conjunto en un claro exponente de la existencia de una vía natural de intercambio de influencias culturales entre el Alto Guadalquivir y el Sureste peninsular. El significado de las figuras que alberga estaría relacionado con rituales que vinculaban las actividades de subsistencia de sus autores con divinidades o fuerzas protectoras y/o relacionadas con la fecundidad. Estas especiales características y su ubicación dentro de un entorno con arte rupestre levantino avalan su reconocimiento como Patrimonio de la Humanidad.

\section{BIBLIOGRAFIA}

Acosta Martínez, P. (1968): La pintura rupestre esquemática en España, Memorias del Seminario de Prehistoria y Arqueología, núm. 1, Universidad de Salamanca.

- (1984): «El Arte Rupestre Esquemático Ibérico: Problemas de cronología preliminares», Scripta Praehistorica, Francisco Jordá, Oblata, Salamanca, págs. 31-61.

Almagro, M. (1959): “La primera fecha absoluta para la cultura de Los Millares a base de Carbono 14», Ampurias, XXI, págs. 249-251.

almagro Gorbea, M. ${ }^{a}$ J. (1973): Los Idolos del Bronce / Hispano, Bibliotheca Praehistorica Hispana, vol. XII, Madrid. 
Almagro, M. y Arribas, A. (1963): Poblado y necrópolis de Los Millares, Bibliotheca Praehistorica Hispana, vol. III, Madrid.

Alonso, A. y Grimal, A. (1996): El arte rupestre prehistórico de la cuenca del río Taibilla (Albacete y Murcia): Nuevos planteamientos para el estudio del arte levantino, vols. I y II, Barcelona.

Asouerino, M. ${ }^{a}$ D. (1984): “Espacio y territorio en el Neolítico del N.E. de Jaén», Arqueología Espacial, Coloquio sobre distribución y relaciones entre los asentamientos, Seminario de Arqueología y Etnologia Turolense, Colegio Universitario de Teruel, Teruel, págs. 31-40.

- (1992): «Epipaleolítico y Neolitico en el Alto Guadalquivir», I Jornadas. Históricas del Alto Guadalquivir. La Prehistoria, Quesada, págs. 33-52.

Asquerino, M. a D. y LóPEz, P. (1981): «La Cueva del Nacimiento (Pontones)», Trabajos de Prehistoria, 38, Madrid, págs. 109-152.

BreulL, H. (1933-35): Les peintures rupestres schématiques de la Péninsule lbérique, vols. I-IV, Lagny.

BREUIL, H. y BURKITT, M. (1929): Rock Paintings of Southern Andalusia, Oxford.

CABALlero KLINK, A. (1983): La pintura rupestre esquemática en la vertiente septentrional de Sierra Morena (provincia de Ciudad Real) y su contexto arqueológico, vols. I y II, Estudios y Monografías, núm. 9, Museo de Ciudad Real, Ciudad Real.

CABRÉ, J. (1917): Las pinturas rupestres de Aldeaquemada, Comisión de Investigaciones Paleontológicas y Prehistóricas, Memoria núm. 14, Madrid.

Carrasco, J. y otros (1980): Aproximación al poblamiento eneolítico en el Alto Guadalquivir, Publicaciones del Museo de Jaén, núm. 8, Granada.

CARRIAZO, J. de M. (1925): «La cultura del Argar en el Alto Guadalquivir. La estación de Quesada», Sociedad Española de Antropología, Etnología y Prehistoria, IV, Madrid, págs. 173-191.

CóRDoBA, B. y VEGA, L.G. (1987): "Abrigo del Molino del Vadico", Arqueología en Castilla-La Mancha. Excavaciones, 1985, Toledo, págs. 79-85.

González Navarrete, J. (1971): La Cueva de la Diosa Madre, Publicaciones del Museo de Jaén, núm. 2, Jaén.

Hernández, M.; Ferrer, P. y Catalá, E. (1988): Arte rupestre en Alicante, Alicante.

López PAyer, M.G. y SORIA LeRMA, M. (1983): "Problemas cronológicos de la pintura rupestre en la Cuenca Alta del Guadalquivir", Homenaje al Prof. Martín Almagro, vol. I, Dirección General de Bellas Artes y Archivos, Subdirección General de Arqueología y Etnografía, Ministerio de Cultura, Madrid, págs. 385-397.

- (1988): El arte rupestre en Sierra Morena Oriental, La Carolina (Jaén).

- (1992): «Reproducción y estudio directo del arte rupestre en los términos de Jaén y Quesada (Jaén)", Anuario Arqueológico de Andalucia, 1990, vol. II, Actividades Sistemáticas, Dirección General de Bienes Culturales, Sevilla, págs. 339-351.

- (1995), «Historia de la investigación del arte rupestre en la provincia de Jaén (Alto Guadalquivir). Trabajos de campo y metodología científica", Boletín del Instituto de Estudios Giennenses, Homenaje al Prof. Caballero Venzalá, núm. CLIII, Jaén, págs. 367-285.

Maluquer, J. (1975): «El yacimiento prehistórico de Hornos de Segura (Jaén)», Noticiario Arqueológico Hispano, 3, Madrid, págs. 287-305.

Martín Socas, D. y Camalich MASSieu, M. ${ }^{a}$ D. (1982): «La cerámica simbólica y sus problemas (aproximación a través de los materiales de la colección L. Siret)», Cuadernos de Prehistoria de la Universidad de Granada, núm. 7, Granada, págs. 267-306.

MaRTinez Garcia, J. (1981): "El conjunto rupestre de la Rambla de Gergal (Gergal, Almería). Nuevos descubrimientos y apreciaciones cronológicas", Cuadernos de Prehistoria de la Universidad de Granada, núm. 6, Granada, págs. 35-74.

- (1992): «Análisis de un sistema de parentesco en las pinturas rupestres de la cueva de Los Letreros (Vélez Blanco, Almeria)», Ars Praehistorica, tomo 7-8, 1988-89, Sabadell (Barcelona), págs. 183-193.

Pellicer Catalán, M. (1964): «El Neolítico y el Bronce de la Cueva de la Carigüela de Píñar (Granada)", Trabajos de Prehistoria, XV, Madrid.

Pérez Burgos, J.M. (1996), «Arte rupestre en la provincia de Albacete: Nuevas aportaciones», Al-Basit, Revista de Estudios Albacetenses, año XXII, núm. 39, Instituto de Estudios Albacetenses, Albacete, págs. 5-74.

Rodríguez, G. (1979): "La Cueva del Nacimiento", Saguntum, Papeles del Laboratorio de Arqueología de Valencia, 14, Valencia, págs. 33-38. 
- (1997): «Últimos cazadores y neolitización del Alto Segura», Actas del // Congreso de Arqueología Peninsular, Tomo I, Paleolítico y Epipaleolítico, Fundación Alfonso Henriques, Zamora, págs. 405-414.

SARRIón MONTAÑANA, I. (1980): «Valdecuevas. Estación Meso-Neolítica en la Sierra de Cazorla (Jaén), Saguntum, Papeles del Laboratorio de Arqueología de Valencia, 15, págs. 23-56.

Soria LeRMA, M. (1980): La pintura rupestre en el Subbético Giennense, Memoria de Licenciatura, Depto. de Prehistoria, Facultad de Filosofía y Letras, Universidad de Granada.

SORIA LERMA, M. y López PAYER, M.G. (1981): «Estudio tipológico y estadístico de los motivos rupestres del Subbético Giennense. Reflexiones en torno a la cronología del arte rupestre esquemático en la Cuenca Alta del Guadalquivir», Memoria de Actividades II, Grupo de Estudios Prehistóricos, La Carolina (Jaén), págs. 39-58.

Soria Lerma, M. y López Payer, M.G.; Vallejo, M., y Peña, J. (1987): Arte rupestre y hallazgos arqueológicos en Quesada (Jaén), Grupo de Estudios Prehistóricos, Serie monográfica, núm. 5, La Carolina (Jaén).

Soria Lerma, M. y López Payer, M.G. (1989): El arte rupestre en el Sureste de la Península Ibérica, La Carolina (Jaén).

- (1990): "Los calcos inéditos del Collado del Guijarral (Sierra de Segura, Jaén)», Ars Praehistorica, tomo 5-6, 1986-87, Sabadell, págs. 234-245.

- (1992): «El núcleo de Quesada. Sus aportaciones al conocimiento del arte rupestre postpaleolítico" I Jornadas Históricas del Alto Guadalquivir. La Prehistoria, Quesada, págs. 53-86. - (1994): Parques naturales y espacios protegidos de Jaén (Estudio de la Prehistoria y del arte rupestre de los parques naturales de la provincia), Ed. Diario JAEN, Jaén.

- (1999): "Arte esquemático en el Alto Segura. Los abrigos I y II de La Tinada del Ciervo», Rev. de Arqueología, año XX, núm. 214, Madrid, págs. 8-13.

- (en prensa): «Arte esquemático en la Cuenca Alta del Segura. Nuevas aportaciones». B.I.E.G., Jaén.

ZAFRA, N. y PÉrez BAREAS, C. (1995): «Excavación arqueológica de urgencia en el dolmen de La Sabina, Quesada (Jaén)», Anuario Arqueológico de Andalucía, 1992, vol. III, Consejería de Cultura de la Junta de Andalucía, Dirección General de Bienes Cuiturales, Cádiz, págs. 415-420. 